高分子ゲート絶縁膜を用いたフレキシブル 有機電界効果トランジスタの作製*

金 永 龍*1. 落合 鎮康*1 澤 五郎*1 $\cdot$ 内田 悦行*1 小嶋 憲三*1 $\cdot$ 大橋 朝夫*1 · 水谷 照吉 $* 1$

\title{
Fabrication of Flexible Organic Field Effect Transistor Constructed with a Polymer Gate Dielectric Layer
}

\author{
Yonglong JIN*1, Shizuyasu OCHIAI*1, Goro SAWA*1, Yoshiyuki UCHIDA*1, \\ Kenzo KOJIMA*1, Asao OHASHI ${ }^{* 1}$ and Teruyoshi MIZUTANI*1 \\ ${ }^{* 1}$ Dept. of Electrical Eng., Aichi Inst. of Tech., Yakusa-cho, Toyota 470-0392, JAPAN
}

(Received November 10, 20005, Accepted February 11, 2006)

\begin{abstract}
We have fabricated organic field effect transistors constructed with pentacene active layers grown by vacuum deposition, polycarbonate (PC) gate dielectric layers fabricated by spin-coating and polyethylene naphthalate thin films used as substrates. The surface morphology of PC thin films was observed by atomic force microscopy (AFM). It was confirmed that the surface morphology of PC thin films had smoothness at a molecular level, although there was a problem to keep a balance between insulation property and smoothness of the surface. From the performance of the obtained organic field effect transistor, the carrier mobility was estimated to be $0.7 \times 10^{-3} \mathrm{~cm}^{2} / \mathrm{Vs}$, the on/off ratio to be $10^{2}$ and the sub threshold voltage to be $32 \mathrm{~V}$.
\end{abstract}

\section{1. はじめに}

近年，有機トランジスタはシリコン半導体に比べ，フレキ シブル，低コスト，大面積化，作製プロセスの簡単さなどの 特性を持つことから, 盛んに研究されている1-7).

有機トランジスタは MIS (Metal-Insulator-Semiconductor）構造をもつことで，ゲート絶縁膜を介して半導体にか けた電界によりゲート絶縁膜・半導体界面に電荷の蓄積層ま たは空乏層が形成され，ソース・ドレイン電極間のチャネル 部分のコンダクタンスが変化することで動作する. 線形領域 及び飽和領域におけるドレイン電流の式をそれぞれ式(1),

(2)に示す.

$$
\begin{aligned}
& I_{\mathrm{d}}=\frac{W}{L} \mu C_{\mathrm{i}}\left[\left(V_{\mathrm{g}}-V_{\mathrm{t}}\right) V_{\mathrm{d}}-\frac{1}{2} V_{\mathrm{d}}^{2}\right] \\
& I_{\mathrm{d}}=\frac{W}{2 L} \mu C_{\mathrm{i}}\left(V_{\mathrm{g}}-V_{\mathrm{t}}\right)^{2}
\end{aligned}
$$

ここで, $W$ はチャネル幅, Lはチャネル長, $C_{\mathrm{i}}$ はゲート絶 縁膜の単位面積あたりの静電容量, $\mu$ はキャリア移動度, $V_{\mathrm{t}}$ はゲート閾值電圧である。

有機トランジスタの活性層には低分子系と高分子系があ る. 代表的なものとして, 低分子系にはペンタセン, フタロ シアニン系などがあり, 高分子系にはポリフルオレン, ポリ (3-ヘキシルチオフェン) (P3HT) などがある. 低分子系 で, これまで一番高い移動度が報告されたのはペンタセンの $3 \mathrm{~cm}^{2} / \mathrm{Vs}$ である ${ }^{8)}$. ペンタセン分子は平面的でかつ直鎖的 であるため, 分子の長軸が直立した形で基板面上と平行方向 に積層し, 配向することで, 分子間の $\pi-\pi$ スタッキングの 形成によるキャリア移動が起こりやすい，また，基板表面処

\footnotetext{
* 平成17年11月10日 第46回真空に関する連合講演会で発表
}

*1 愛知工業大学電気工学科（テ470-0392 豊田市八草町1247）
理によりペンタセン結晶が大形化することで，より高い移動 度が期待される。

一方, 高分子系の材料は溶液プロセスにより容易に膜が形 成できることで, 印刷技術による低コスト, 大面積化が実現 できるというメリットがあるが, 高分子系材料では分子の無 秩序さがキャリア移動度を小さくする要因となる. したがっ て, 高分子系材料に打いては, 分子間の規則性を持たせるこ とでより高い移動度を実現するための探索が必要である.

絶縁層には従来, 酸化膜を使うことが主流であるが, 近年 は高分子材料を使うことも多くなっている，すでに，ポリイ ミド $(\mathrm{PI})^{6)}$, ポリメタクリル酸メチル $(\mathrm{PMMA})^{9)}$, ポリビ ニルアルコール $(\mathrm{PVA})^{10)}$ などを絶縁層に用いたトランジス タの報告がある。 また，基板にも高分子材料のポリエチレン テレフタレート (PET), ポリエチレンナフタレート (PEN) などを使い, 有機トランジスタの透明性, フレキシブルな特 性を生かすことができ, 光エレクトロニクスへの応用が期待 される. 本研究では, ペンタセンを活性層とし, ポリカーボ ネート（PC）を絶縁層, PEN を基板とする透明で, フレキ シブルなトランジスタを作製し，その性能を評価する。

\section{2. 実験方法}

本研究ではボトムコンタクト構造のトランジスタを作製 し, 性能評価する. 有機電界効果トランジスタ（OFET）の 構造図および電気特性の測定回路図を Fig. 1 に示す。作製 手順として, はじめに PEN 基板上にゲート電極を真空蒸着 法によりシャドーマスクを使って蒸着する．次にクロロフォ ルムを溶媒とした $6.7 \%$ の PC 溶液を用い, スピンコート法 により $6000 \mathrm{rpm} ， 10$ 秒で PC 膜を作製する．PC 膜上にシャ ドーマスクを使ってチャネル長 : $100 \mu \mathrm{m}$, チャネル幅 : 2 $\mathrm{mm}$ のソース・ドレイン電極を真空蒸着法により作製し, 最 後に真空蒸着法によりペンタセンを蒸着する. ペンタセンの 


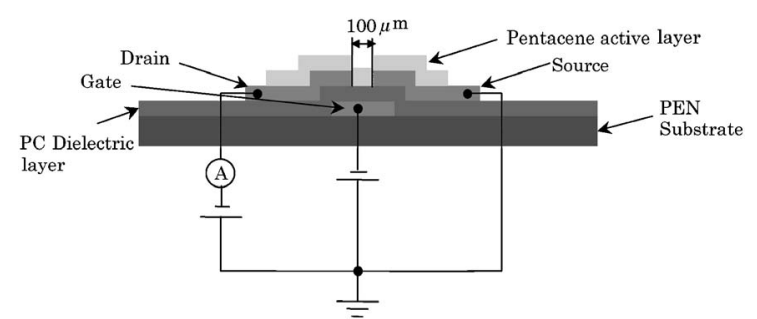

Fig. 1 Sample structure and electrical circuit for the transistor measurement.

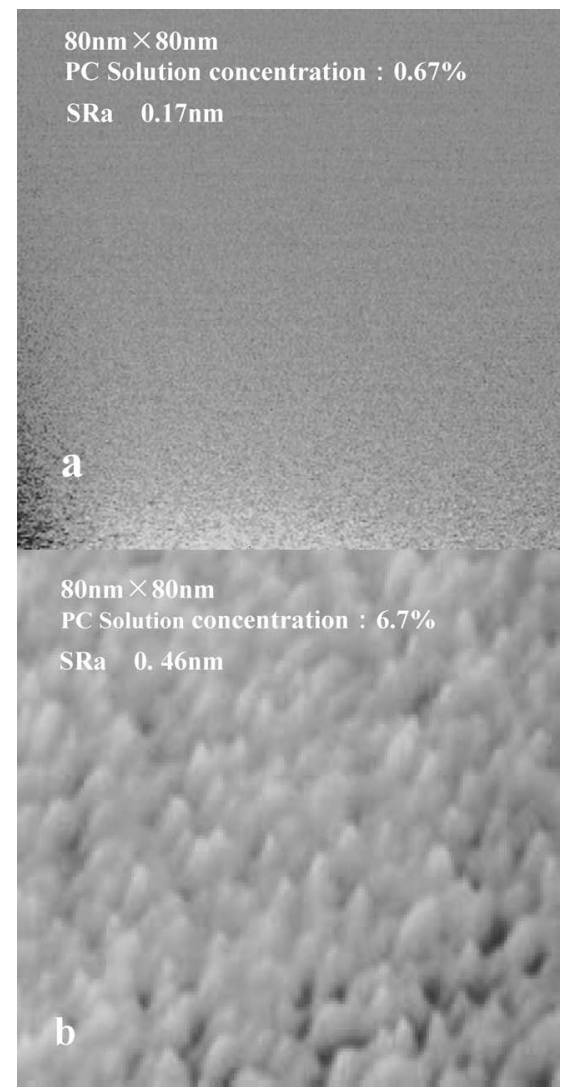

Fig. 2 AFM images of the surface of the PC thin films.

蒸着条件として, 蒸発源温度 : $210^{\circ} \mathrm{C}$, 基板温度 : $70^{\circ} \mathrm{C}$, 蒸 着時間： 2 時間にし，蒸着後にアニール処理を 2 時間施し た。作製されたペンタセン薄膜の形態と配向を X 線回折装 置（XRD）［島津製作所侏製，原子間力顕微鏡（AFM） [NV-2000型オリンパス陎製］で検討した。また，FETの $\mathrm{I}_{\mathrm{D}}-\mathrm{V}_{\mathrm{D}}$ 特性を評価し，キャリア移動度を見積もった。

\section{3. 実験結果及び検討}

Fig. 2 に0.67\%のPC 溶液と6.7\%のPC 溶液を用いて作 製した PC 膜表面の AFM 像を示す． $0.67 \%$ のC 溶液で作 製した PC 膜では，表面が分子レベルで平滑である。しか し，膜厚が $70 \mathrm{~nm}$ 以上にできないため, 絶縁層上に $\mathrm{Au}$ 電極 が蒸着されるときに熱で破壊される。素子の作製には， 6.7 \%の PC 溶液で作製した PC 膜を用いた．Fig. 2(b) から分か るように，6.7\%の溶液で作製した PC 膜では表面平滑さが 悪くなり，表面に凹凸が現れる。これらの凹凸はキャリアの
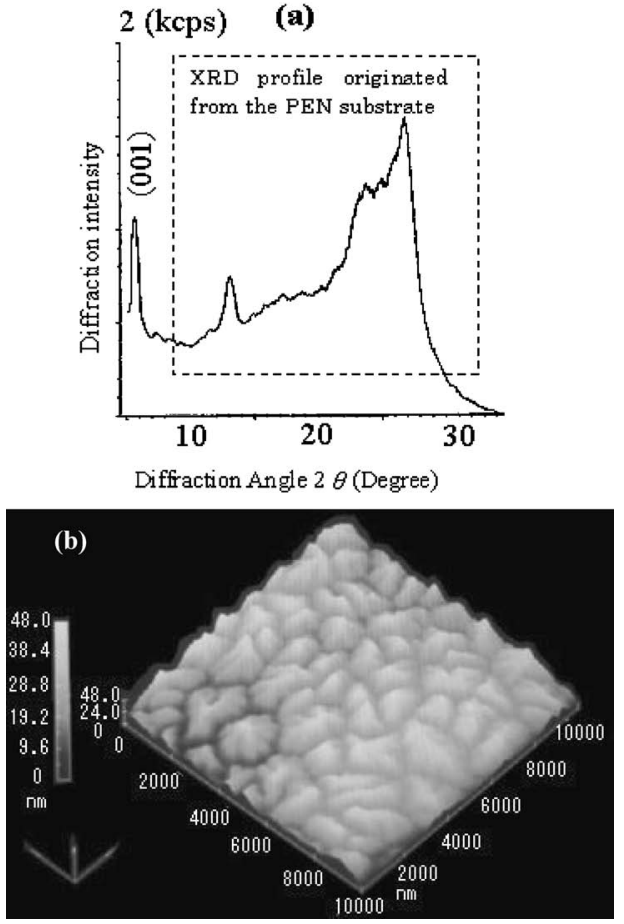

Fig. 3 XRD profile (a) and AFM image (b) of the pentacene thin film evaporated on a $\mathrm{PC}$ thin film at $25^{\circ} \mathrm{C}$.
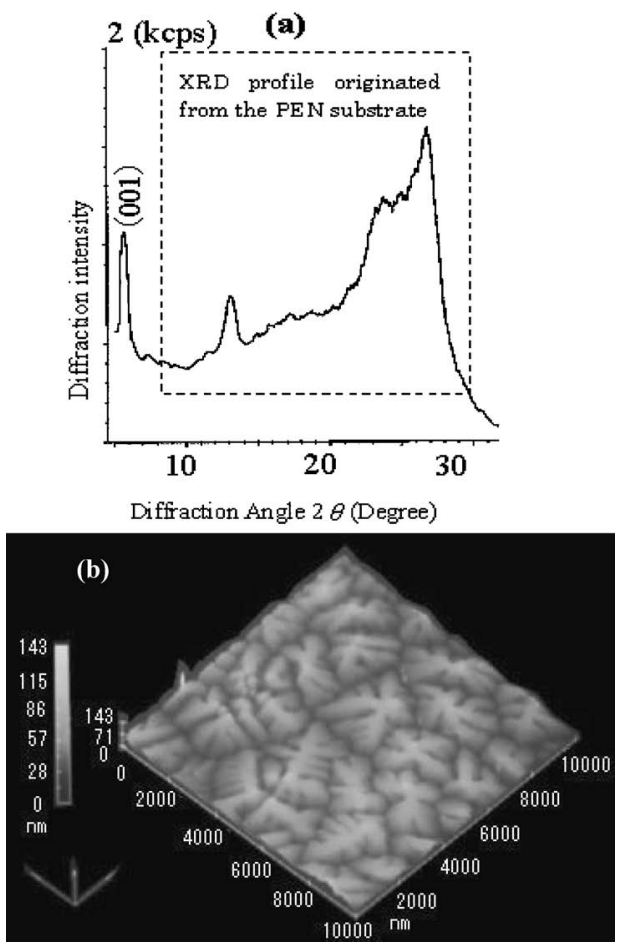

Fig. 4 XRD profile (a) and AFM image (b) of the pentacene thin film evaporated on a $\mathrm{PC}$ thin film at $70^{\circ} \mathrm{C}$ and annealed at $70^{\circ} \mathrm{C}$ for $2 \mathrm{hrs}$.

トラップサイトとなり, 電流を小さくする要因となる. 今後 絶縁層表面の平滑さを改善していく必要がある.

Fig. 3〜4 に PC 膜上に異なる条件下で作製されたペンタ セン膜の XRD プロフィール抢よび AFM 像を示す．XRD プロフィールに打いて，いずれの膜もペンタセン結晶の 

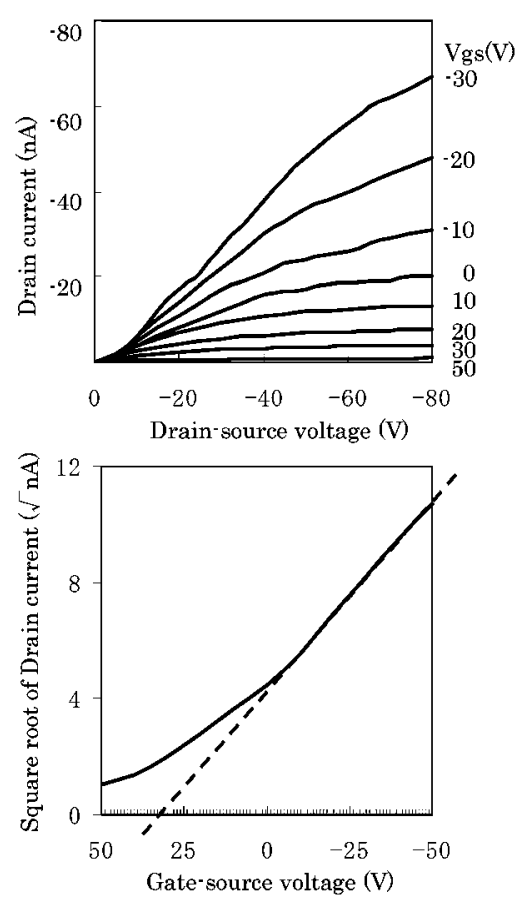

Fig. 5 Transistor characteristics of the organic field effect transistor.

(001)面の回折ピークが現れることから，ペンタセン分子が $\mathrm{c}$ 軸配向していることが分かる. $\mathrm{AFM}$ 像から， $70^{\circ} \mathrm{C}$ の基板 温度で蒸着後, 2 時間アニール処理されたペンタセン薄膜 で, 結晶成長が確認される. しかし, 最大の結晶が $2 \times 3 \mu \mathrm{m}$ で, チャネル長の $100 \mu \mathrm{m}$ に比べると小さい.この場合，キ ヤリアが結晶界面でトラップされ，移動度が小さくなること が推察できる。この解決には，チャネル長を $2 \mu \mathrm{m}$ 以下に微 細化するかあるいは $100 \mu \mathrm{m}$ 以上の大きな結晶を作る必要が ある。

Fig. 5 に PEN 基板上に作製された FETの $\mathrm{I}_{\mathrm{D}}-\mathrm{V}_{\mathrm{D}}$ 特性を 示す。典型的な FET 静特性が得られた。見積もられた移動 度は $\mu=0.7 \times 10^{-3} \mathrm{~cm}^{2} / \mathrm{Vs}$, 閾值電圧は $V_{\mathrm{TH}}=32 \mathrm{~V}, \mathrm{ON} /$ OFF 比は $10^{2}$ である. 電流の值がまだ小さいが，これはゲー 卜絶縁層の界面平滑度や, 電極からのキャリア注入効率の不 十分さに関係すると考えられる。したがって，絶縁層・活性 層界面の改善などにより, より高い移動度や $\mathrm{ON} / \mathrm{OFF}$ 比が 期待される.

\section{4. よ め}

$\mathrm{PC}$ 膜上で高配向性のペンタセン結晶が得られた。 また, ゲート絶縁層に PC 膜, 活性層にペンタセンを用いて作製し た OFETで，典型的な FET 静特性が得られた。見積もられ た移動度が $\mu=0.7 \times 10^{-3} \mathrm{~cm}^{2} / \mathrm{Vs}$, 閾值電圧が $V_{\mathrm{TH}}=32 \mathrm{~V}$, $\mathrm{ON} / \mathrm{OFF}$ 比が $10^{2}$ になる. 実用的には， $\mu$ が $1 \mathrm{~cm}^{2} / \mathrm{Vs}$ 以上, $V_{\mathrm{TH}}$ が $0 \mathrm{~V}, \mathrm{ON} / \mathrm{OFF}$ 比が $10^{6}$ 以上必要である.これらの值 と得られた值の比較から，作製された OFETの性能が低い ことが分かる．これらの值の改善には，ゲート絶縁層表面の 平滑化をすること, 電極からのキャリア注入を増大すること が重要である。したがって, 絶縁層・活性層界面の改善, 注 入量の増大により, OFF 電流が十分小さく, 高移動度, 高 い $\mathrm{ON} / \mathrm{OFF}$ 比が期待される.

今後の課題として, 絶縁層 - 活性層界面の改善, 電極の作 製法, 活性層の改善などにより，より大きな移動度，高い ON/OFF 比をもつOFETの作製の実現を目指す。また，安 価, 大面積などを実現するため, 活性層の溶液プロセスによ る作製技術を確立する必要がある。

\section{謝辞}

本研究は, 文部科学省私学助成学術フロンティア事業 「21世紀を支えるための材料の開発一環境, エネルギー, 情 報に資する材料開発のための基礎研究—」(平成 $14 \sim 18$ 年度) の研究の一環として行われたものである.

\section{〔文献〕}

1) M. Yoshida, E. Uemura, S. Hoshino, N. Takada, T. Kodzasa and T. Kamata: Jpn. J. Appl. Phys., 44 (2005) 3715.

2) A. Zen, J. Pflaum, S. Hirschmann, W. Zhuang, F. Jaiser, U. Asawapirom, J. P. Rabe, U. Scherf and D. Neher: Adv. Funct. Mater., 14 (2004) 757.

3) J. Lee, K. Kim, J. Kim, S. Im and D. Jung: App. Phys. Lett., 82 (2003) 4169.

4) H. Klauk, M. Halik, U. Zschieschang, F. Eder, G. Schmid and C. Dehm: Appl. Phys. Lett., 82 (2003) 4175.

5）安田 剛, 筒井哲夫：応用物理, 第 74 巻, 第 9 号 (2005) 1196.

6) Y. Kato, S. iba, R. Teramoto, T. Sekitani and T. Someya: Appl. Phys. Lett., 84 (2004) 3789.

7) T. Sekitani, S. Iba, Y. Kato and T. Someya: Jpn. J. Appl. Phys., 44 (2005) 2841.

8) H. Klauk, M. Halik, U. Zschieschang, G. Schmid and W. Radlik: J. Appl. Phys., 92 (2002) 5259.

9) J. Puigdollers, C. Voz, A. Orpella, R. Quidant, I. Martin, M. Vetter and R. Alcubilla: Organic Electronics, 5 (2004) 67.

10) Sung HunJin: SMDL Annual Report 2003. 